\title{
A call to action: organizational, professional, and personal change for gender transformative WASH programming
}

\author{
Sue Cavill, Naomi Francis, Melita Grant, Chelsea Huggett, \\ Caitlin Leahy, Lee Leong, Elaine Mercer, Jamie Myers, \\ Mascha Singeling, and Tom Rankin
}

\begin{abstract}
The Sustainable Development Goals (SDGs) and targets aimed at improving access to water, sanitation, and hygiene (WASH) are also an opportunity for the transformation of gender norms. To facilitate this transformation, this paper makes a call to action for global and national efforts for organizational, professional, and personal change. Several NGOs are leading a process towards a more reflective and transformative approach. This paper presents a number of examples - from headquarters, and others from country offices and research institutes - of the changes under way to support a stronger connection between the 'outer faces' of WASH professionals in the sector and the individual, personal inner spaces. The paper concludes with a set of recommendations for personal and organizational change.
\end{abstract}

Keywords: personal change, transformation, gender, empowerment, WASH, NGOs

Do not leave yourself behind as you work to ensure no one is left behind (Srilatha Batliwala, Keynote at RDI Conference, 2019).

TO DATE, THE GLOBAL WASH SECTOR has integrated gender equality strategies to varying degrees along a continuum (see Figure 1): from a focus on women's reproductive and care roles in the household (van Wijk-Sijbesma, 1987) towards those with a focus on 'strategic needs' (Moser, 1989). Strategic needs are those that contribute to changing social norms, through changing status or changing power relations, particularly between women and men. To do this, the causes, and not just the consequences, of existing inequalities are uncovered and focused upon. In support

Sue Cavill (sue.cavill@outlook.com) freelance consultant, UK; Naomi Francis (naomi.francis@unimelb.edu.au) Research Fellow, University of Melbourne, Australia; Melita Grant (Melita.grant@uts.edu.au) Research Principal, Institute for Sustainable Futures, Australia; Chelsea Huggett (Chelsea.Huggett@wateraid.org.au) Equity Inclusion and Rights Advisor, WaterAid Australia; Caitlin Leahy (Caitlin.Leahy@uts.edu.au) Senior Research Consultant, Institute for Sustainable Futures, Australia; Lee Leong (Lee.Leong@plan.org.au) Senior Advisor, WASH, Plan International Australia; Elaine Mercer (e.mercer@ids.ac.uk) Communications and Networking Officer, Sanitation Learning Hub, UK; Jamie Myers (j.myers2@ids.ac.uk) Research and Learning Manager, Sanitation Learning Hub, UK; Mascha Singeling (mascha.singeling@plannederland.nl) Senior WASH Programme Manager, Plan International Netherlands; Tom Rankin (tom.rankin@plan.org.au) Program Manager, WASH, Plan International Australia

(C) This open access article is published by Practical Action Publishing and distributed under a Creative Commons Attribution Non-commercial No-derivatives CC BY-NC-ND license http://creativecommons.org/licenses/by-nc-nd/4.0/, ISSN: 0262-8104/1756-3488 

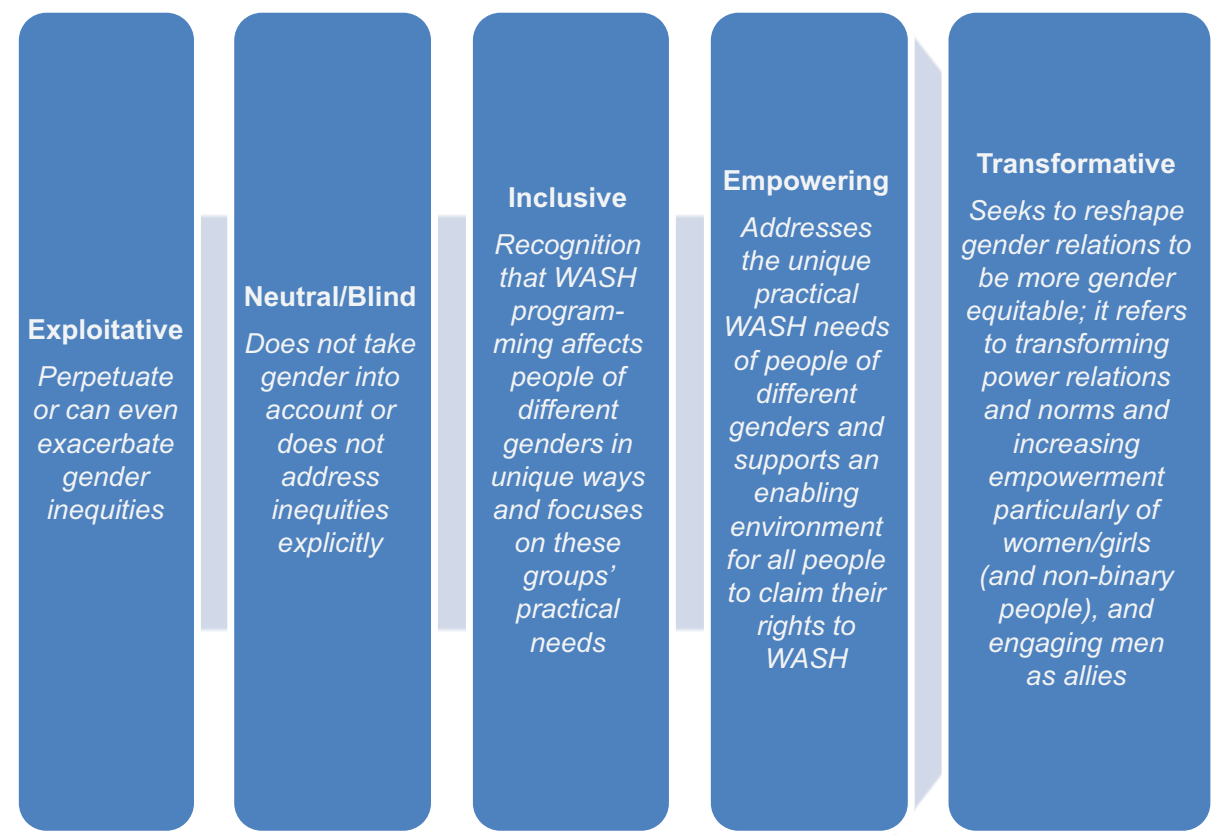

Figure 1 Continuum of approaches related to gender equality Source: adapted from Gupta, 2001 in Grant et al., 2017, 2019

of the focus on strategic needs, more recently, WASH practitioners and experts have started considering what a 'gender transformative' approach might look like and seeking to move WASH interventions along the continuum.

WASH programmes can be an entry point for inclusion and transforming socially determined roles and relations for women, people with disabilities, and other excluded groups. As outlined in Figure 1, a transformative agenda seeks to reshape gender relations to be more gender equitable, and refers to transforming power relations and norms and increasing empowerment particularly of women/ girls (and non-binary people), as well as engaging men as allies (Gupta, 2001). However, like other sectors, the WASH sector has a way to go to better understand and address gender equity issues beyond 'women' and binary conceptions of gender, so as to also include sexual and gender minorities (SGM) and other marginalized individuals and groups (Boyce et al., 2018). There is also more to do to tackle ableism, the beliefs or practices that devalue and discriminate against people with physical, intellectual, or psychiatric disabilities in support of a rights-based approach to development (Smith, n.d.). In support of this, WASH actors are increasingly reflecting on positionality, which is the social and political context that creates identity in terms of race, class, gender, sexuality, and ability status. Positionality also describes how identity influences, and potentially biases, an individual's understanding of and outlook on the world (Dictionary.com, n.d.). 
It is not possible to do genuine gender norms transformative work without understanding how patriarchal structures, beliefs, and attitudes intersect with other power structures and layers of discrimination such as race, class, and ableism (Soeters et al., 2019) (see Figure 2).

While recognizing the good work that is already happening in the WASH sector related to improving gender equality in myriad contexts, the purpose of this paper is to make a call to action to build on this momentum by intentionally including often forgotten 'ingredients' for transformative WASH programmes - personal and professional development - which could potentially accelerate and sustain efforts towards transforming gender norms. We are also responding to Srilatha Batliwala's call to dismantle 'deep structures' in order to enact more gender equal and just practices (Batliwala, 2011). Deep structures refers to 'hidden sites and processes of power and influence, the implicit culture, the informal values and systems of reward and recognition' in an organization and it is within these deep structures that individuals' internalized attitudes and behaviours are manifested (Batliwala, 2011). Therefore, personal and professional development are crucial to revealing and dismantling these structures in our WASH organizations. Gender transformation is required at all levels in the WASH sector: individual (staff), programme, organization, donor, government, and partner level. This transformation towards equality is needed by all WASH actors, and not only those in the Global South, given inequality exists and persists in all country contexts. This requires those working in the WASH sector to undertake our own reflective learning, examining our unconscious bias and the ways in which our sector itself is gendered, racially biased, ableist, and so on, and reflecting on what this means for our own work and our partners' work as well as for the communities in which we work. This paper is written by a group of individuals based in development organizations and research institutes in the Global North, where there has been less attention to the examination of personal changes in beliefs, attitude, and behaviours to date.

\section{A new imperative for development organizations: an opportunity for progress}

Development organizations often place gender equity at the centre of their mandates and are committed to gender parity in the workplace (Eyben and Turquet, 2013). This organizational commitment can gradually be translated into WASH sector culture, operations, and programmes where there has traditionally been a lack of representation of women and potentially marginalized groups (such as people from underprivileged backgrounds, people with a disability, or people within sexual and gender minorities). For example WaterAid changed the toilet facilities in their London office to be more inclusive of staff or visitors who do not identify as male or female genders (such as people who are transgender, intersex, or neither male nor female) (Nath et al., 2017). An organization's WASH programme may be ahead of the broader organization's commitment to gender equity, and it may be through the WASH programme that a clear commitment to gender equality is demonstrated. 


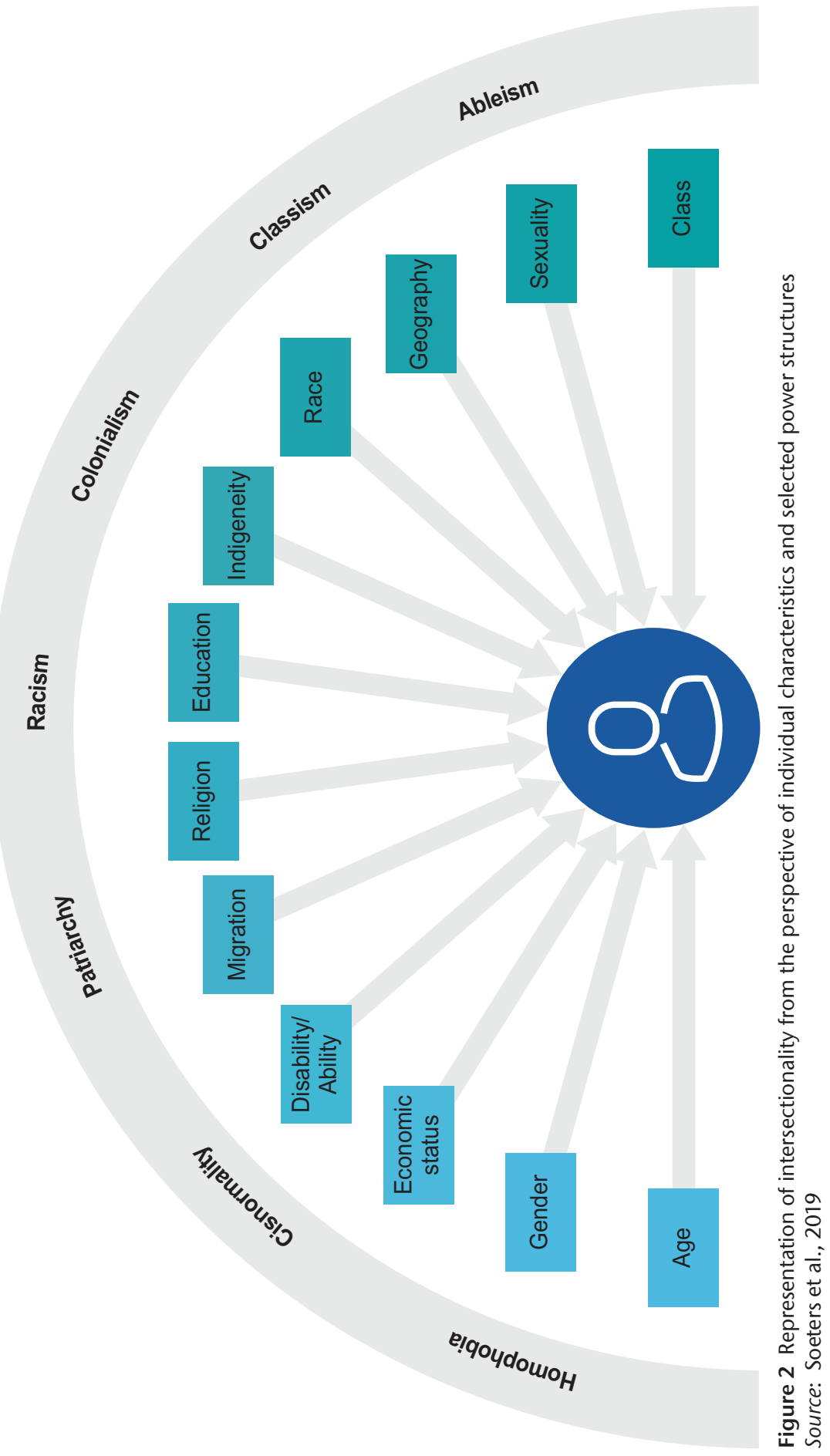


Progress towards gender equality needs to be led at all levels of society, from governments to donors, individuals, and civil society movements and corporations. Donors and development partners also have an influence and responsibility in promoting the gender equality/transformative agenda: for example, through initiatives such as the Australian Government's A \$110 m Water for Women Fund (Department of Foreign Affairs and Trade, n.d.). Canada has also launched a feminist aid programme and budget (Government of Canada, 2017). By 2021-22 at the latest, the Government of Canada also has made a commitment that at least 95 per cent of bilateral international development assistance investments will either target or integrate gender equality and the empowerment of women and girls. The Swedish Government has a feminist foreign policy (Government Offices of Sweden, n.d.). The policy is accompanied by an action plan with the direction and measures for 2020.

Individuals can also make pledges for gender transformative change (through programmes such as HeforShe and Healthy Manhood; Agora, n.d.; A Call to Men, n.d.). Civil society has led social movements and society towards gender norms transformation, and research has commenced in the WASH sector on how genuine partnerships with national change agents and movements (with feminist movements and SGM organizations) as well as universities, private sector, or other WASH sector actors can support transformative change to occur (ISF-UTS, 2019). Corporations also play an important role, and programmes to engage leadership such as the Male Champions of Change (n.d.) programme are proving to be catalytic in the corporate space.

\section{NGO policies on equity and inclusion}

There are cases of NGO staff sexually abusing women and children, and this has led some NGOs to take significant measures to look at their own cultures, dig deep, and identify how to reveal and deal with the root causes of sexism within organizations. As offered by Winnie Byanyima (2019, in her role as Executive Director of Oxfam International): 'Culture, culture, culture: that's the biggest focus now for change for Oxfam and organizations like ours. Our big challenge isn't only in writing new rules but tackling hard the root causes of sexual abuse. We need to reform age-old harmful socialized sexist ideas and build a culture that repudiates abuse and affirms equality and dignity.' Crises where individuals within organizations have committed sexual misconduct and/or harassment of staff or community members is a stark reminder of the need to be vigilant, and invest in ensuring that staff are deeply committed to the values of the organization.

There are many ways in which the WASH sector may itself be gendered, racially biased, or ableist. For instance, within an organization we may find examples of the personal biases of individuals violating the formal policies of the organization such as manifestations of transphobia or homophobia (REDR, 2016). Biases might take more innocuous forms such as: everyday racism (Essed, 1991), selective incivility (Cortina et al., 2013), micro-aggressions (Sue et al., 2007), subtle discrimination (Rowe, 1990), or implicit and explicit bias (Quillian, 2006: 319). If these behaviours are present, the workplace culture has significant implications for female and minority employees, the quality of our work, and its potential to be 
transformative. Instances where 'a charity's internal culture and leadership behaviours appear to be at odds with the high ideals of its mission' (Charity Commission for England and Wales, 2020) require deep cultural changes, not only dealing with the individuals.

It is important to ask ourselves if and why there is a disconnect between the extent to which WASH organizations and actors promote gender equity in the communities which they seek to serve and the extent to which they promote and demonstrate equity, inclusion, and non-discrimination in their policies, practices, and organizational cultures? Any disconnect risks reproducing the power relations, exclusion, and sense of privilege that we say we are trying to change in the world outside (Batliwala, 2019).

To begin to explore whether or not a disconnect exists from a sectoral perspective, the rest of this paper asks some key questions including:

- Can WASH organizations implement and advocate for gender transformative WASH programmes, both in the Global North and the Global South, if they themselves are not 'transformed'?

- What processes have WASH organizations put in place to support gender equity and inclusion within their own organizations?

Bringing about gender norms transformation in the communities which programmes seek to support requires efficacy as well as authenticity and undertaking gender norms transformation in ourselves and our own organizations can help to bring both these things about.

Personal and organizational change is needed within: 1) headquarter/donor/'expert'/ research organizations and staff (often from the Global North), as well as in 2) the communities in which we work; 3 ) government agencies, and in policies and practice; and 4) partner organizations and staff in focus countries. To date, transformation has been aimed at target communities and governments, but less so on partner organizations and headquarter/donor/'expert' organizations. While staff have often been trained on how to consider Gender Equality and Social Inclusion (GESI) in programming, their own personal transformation (at field and headquarter levels) has received less attention, and even less is known about how effective the training is in shifting mind-sets and personal and professional practice. Even when staff have been trained on GESI at the organizational level, this does not always influence their personal views for the reasons discussed below. There is the opportunity to ensure that individuals and the organizations they sit within across the WASH sector deeply hold and exhibit gender norms transformative values and behaviours. Additionally, WASH staff should not undervalue their ability to influence organizational culture and drive the organization itself to be more transformative.

\section{Development organizations need to transform themselves first}

Obviously, personal values play an important role in shaping the occupational choices and work behaviour of WASH actors. Staff typically internalize the organizational visions and values, as well as the standards and norms of their professional 
field (for example as engineers or health professionals, and the human right to development). At the field level, WASH projects generally have GESI trainings and refreshers for implementing staff to 'deliver' WASH projects that are transformative in terms of gender equity and addressing other forms of discrimination. There are tools that can assist in implementation, such as Longwe's (1999) Empowerment Framework, and the four types of power as articulated by Rowlands, Kabeer, Cornwall, and Batliwala (Grant et al., 2019), as well as tools to measure empowerment, such as the Empowerment in WASH index (Dickin and Bisung, 2018).

Few WASH projects support (and track) changes in staff attitudes, beliefs, behaviours, and practice of GESI - either at field, donor, expert, regional NGO, or headquarter level. This is potentially in part due to the fact that attitudes and beliefs are hard to understand in terms of behaviour. There are also a range of ways that beliefs could be displayed at work and in the community. Table 1 illustrates different levels of conformity between private beliefs and public behaviour.

Table 1 Levels of conformity between private beliefs and public behaviour

Compliance
Adentification person changes their public behaviour, the way they act, but not their private beliefs
they are in the presence of the group
Internalization
A person changes their public behaviour, their private beliefs, and private behaviour,
such as not speaking over or for marginalised peoples, negotiating roles and
responsibilities not along gendered lines and expectations, not using their own
power and privilege to advantage themselves over others in public or private.

Source: Adapted from Tutor2U, n.d.

WASH professionals may change their public behaviour or their private beliefs (or both) in line with expectations at work (compliance or identification). This may be the result of normative social influence, that is, 'the influence of other people that leads us to conform in order to be liked and accepted by them' (Aronson et al., 2005), and staff may hold different behaviours and beliefs at home or outside work.

Another benefit of organizations focusing on transforming their staff and organizational culture is increased congruency between organizational culture and values, and those that they espouse to the world. Congruency between personal and organizational values is also important: a lack of alignment is likely to result in a disconnection between WASH actors and their employers, tensions in doing the work, greater intention to leave, and higher staff turnover. Strong alignment may have higher job satisfaction, organizational and team commitment, motivation, feelings of success, and greater concern for target communities. Internalization of beliefs is thought to be more effective and authentic for transformative change. How can organizations best facilitate this, given the challenges of the blurred boundary between organizational and personal beliefs and behaviours?

The move towards WASH actors doing more gender equity work has meant more collaboration (or at least consultation) with feminist and women's organizations, mass movements (e.g. the Viet Nam Women's Union), and SGM organizations. 
The increase in such partnerships has likely been born from a recognition of the mutually supportive goals of gender equality and WASH, and the foundational nature of each for achieving mutual goals. This has raised awareness of the depth of change needed in the WASH sector and a realization that our organizations (and partners) need to demonstrate internalised gender norms transformation to fully pursue social change, mitigate risks, and to ensure organizations are more effective in delivering their mission.

\section{A vision for transformative WASH: what would change look like?}

Pursuing transformation in development requires authentic change, underpinned by learning, reflection and sharing. As a sector, WASH professionals are becoming more self-critical of their work and are increasingly promoting a culture of learning and sharing (see the 'Nakuru Accord: Failing better in the WASH sector' (University of Leeds, n.d.; Grant et al., 2016; Grant and Willetts, 2019). Chambers (1993: 118) advocates a reversal of normal bureaucracy and professionalism in three domains procedural, professional, and personal - 'These reversals imply more downward accountability; a professionalism which values and respects people and the individual; and personal commitments which seek to serve those who are weaker and more deprived, accepting and celebrating diversity'.

In an assessment of how WASH NGOs learn, Grant and Willetts (2019) found that WASH sector practitioners were seeking more opportunities to stop and reflect on their learning and use this to fold into their practice. In this vein, several NGOs are leading a process towards a more reflective and transformative approach. For instance, in India and Timor-Leste, CARE added a staff commitment to stimulating personal change as the first step in the programme cycle prior to doing so with communities as part of their 'Social Analysis and Action (SAA) Approach'. In this approach, staff's ability to self-reflect, communicate, and facilitate is considered to be the beginning of the social transformation (CARE, 2017). Promoting personal change in staff is the necessary pre-condition to promoting community-level change.

A vision for transformative WASH reflects at least three principles, developed by CARE (2008) as part of the Inner Spaces Outer Faces Initiative (ISOFI), which are instructive:

1. Development practitioners need space to explore and understand their own values, attitudes, beliefs, and experiences.

2. Personal learning and change is critical to enhancing organizational effectiveness.

3. Processes and practice in the professional sphere should encourage people to recognize and maximize this in their lived experience.

These examples illustrate how we might re-shape ourselves to be better placed to respond to the challenges we face. It is increasingly clear that such changes are necessary, inevitable, and unavoidable. And that the changes called for are radical, far-reaching, and fundamental. 


\section{Building a context for change}

We recommend that in order to deliver gender transformative programmes all WASH sector actors including donors, governments, development partners, universities, experts, private sector, and project and implementing staff must reflect on and change their own mind-sets and practices related to gender roles and responsibilities, in part through a better understanding of their own positionality. Gender transformative programming must move beyond the organization to individual changes in attitudes, so that approaches are not gender blind, or inadvertently harmful. WASH actors can be role models and examples for their colleagues and communities: to contribute to - and lead - social change. In this way, WASH actors can also live the experience of gender norms transformation.

The following examples illustrate some of the changes under way to support a stronger connection between the 'outer faces' of WASH professionals in the sector and the individual, personal inner spaces. There are some examples from headquarters, and others from country offices and research institutes. These examples provide an overview of the depth of effort required to work towards genuine gender norms transformation.

\section{Example 1: Unconscious biases session with Yayasan Plan International Indonesia (YPII)}

YPII's project, entitled 'WASH and Beyond -Transforming Lives in Eastern Indonesia' is a four-and-a-half-year project (that commenced in 2018) supported by Plan International Australia (PIA) and DFAT through the Water for Women (WfW) Fund. As part of GESI good practice, the project design has built in ongoing training and coaching on GESI for staff, throughout the life of the project. So far this has included GESI trainings, GESI WASH workshops, Plan's Gender and WASH Monitoring Tool (GWMT) training and roll out (Plan International, 2018), and gender diversity and inclusion workshops (such as working with people with different disabilities). One such workshop (in July 2019) explored the team's unconscious biases. As this session may be of benefit to others in the sector to undertake, the following outlines the content and process that was used.

Understanding what unconscious biases are. Through presentation and discussions, the team came to understand that the human brain uses mental shortcuts to automatically process information which can be useful. On the other hand, unconscious biases can also contribute to discrimination along the lines of race, age, gender identity, sexual orientation, abilities, religion, weight, appearance, and so on (Re:Work, n.d. Unbiasing). Individually, our 'unconscious bias is far more prevalent than conscious prejudice and often incompatible with one's conscious values' (Office of Diversity and Outreach, n.d.).

Discussing why unconscious biases are important. Further discussions dug deeper to understand that biases, including those about gender and other factors, largely inform an individual's pattern of behaviour, including decisions within project teams and organizations. This can include decisions about 'what' and 'how' 
GESI-responsive the design and implementation of a WASH project is. This also extends to how an individual treats and interacts with others in their team, organization, project partners, and importantly, those in the communities, including the most marginalized people. Being more conscious of one's unconscious biases requires individuals to look and reflect inwards, and consider what implications this has for whether they 'walk the walk, and talk the talk' about gender and social inclusion.

Exploring individual unconscious biases. Through the online Harvard University Implicit Association Test (IAT), team members were able to start exploring their own thinking about their unconscious biases. In small groups, the team then looked at several pre-prepared statements that could be said within a project team or organization. This exercise revealed how simple statements can result in, or reinforce, stereotyping bias. Individuals reflected on how they have experienced, or witnessed the use of similar statements in their lives and the impacts these had.

Commitments. Based on the exploration within this session, the team made personal (individual) commitments to increase their self-awareness of the potential impacts of their own unconscious biases, and professional (team) commitments in the form of ways of working agreements (e.g. behaviours towards each other). This ensured that everyone could walk away from the session with some practical actions.

As the project will continue until December 2022 the team has started to have, and will continue to have, ongoing coaching (on unconscious bias, among other topics) including a psychologist who specializes in working in teams. Additionally within the project's annual review meetings, staff GESI knowledge and attitudes will be explored (and summarized for group monitoring and evaluation). The above unconscious biases session supports the project teams on their transformative journey and will hopefully inspire other WASH sector actors to invest in the same.

\section{Example 2: Equality and inclusion in WaterAid}

Under their Equality and Inclusion framework, WaterAid Australia and country programmes in Papua New Guinea, Timor-Leste, and Cambodia have undertaken a range of transformative changes to demonstrate their commitment to equality, inclusion, and rights, including by ensuring the organization and workforce is inclusive. Accessibility audits of WaterAid offices have been carried out (by local disability organizations where possible), job descriptions all have a reference to equality and inclusion, and all staff have access to organizational policies which refer to the inclusion of all people regardless of gender, ability, age, HIV/AIDS status, and sexuality. A gender audit in 2019 formed the basis for action plans across teams and the organization to address gender equality. Workforce demographics (including factors such as age and sex) are used to inform recruitment policies and processes. All WaterAid staff receive mandatory training on equality and inclusion so that staff are sensitive and confident in working with people from marginalized groups. 
Leadership behaviours, person and job specifications, inductions, performance management, and personal development plans reflect a commitment and accountability to equity and inclusion. The employment of people with disabilities is promoted across all levels of the organization. Such an approach aims to achieve congruency between what is expected of organizational and government staff in low-income countries as well as staff in high-income countries. While there are no indicators on whether the intended changes have been successful, at an individual level, the gender audit findings and action plans provide an accountability mechanism to track progress on an annual basis.

\section{Example 3: Plan International Australia's Water for Women project in Solomon Islands}

While GESI training is important and necessary, understanding how this translates (or does not) into actions, words, and behaviour of staff is not well known. Plan International invested in staff's understanding of GESI and found that staff had profound new understandings from the experience.

Plan's Water for Women project in Solomon Islands invested heavily in strengthening staff's understanding of gender and social inclusion and reinforced this by, among other initiatives, training on Plan's Gender WASH Monitoring Tool (GWMT), which has been found to indirectly change staff mind-sets and practices. For example, one male attendee of the training responded that he'd never really stepped back and considered the unequal WASH workloads in his household and the implications this had for other wives and daughters. Unequal household workloads are so culturally embedded that they are often not reflected on by men. Such domestic roles are so entrenched that during customary wedding ceremonies in Solomon Islands, the new bride is required to clean around the house in front of the crowd who pile rubbish up. Facilitating discussion and analysis with communities regarding unequal distribution of WASH workloads exposes staff to many stories of household inequalities and prompts them to analyse the community situation. During GWMT training they are also prompted to consider their own homes, both when they were young and now. Female staff have also reflected positively on the impact that the training has had by opening up their personal views, that were somewhat blinded by social norms into accepting the high workloads and low decision-making power of women at home and in communities.

However, personal transformation can be more complicated than professional transformation. Plan's Country Manager reported that in the context of Solomon Islands, women's roles and responsibilities are business as usual no matter the title that one holds regarding work plus one's status in the society.' She explains the challenges that she and her female counterparts have faced in changing social norms and expectations within their own households despite their high profile work on gender advocacy in the public domain. In her household, as an example, she says that 'five days a week, I cooked the dinner. Every morning, I am responsible to ensure that there is hot water for tea.' 
Similarly, a District WASH Manager reported that in Timor-Leste, 'I do not feel [my] position makes me have to avoid homework like a housewife who, after working in my office, still remains housewives such as cooking, washing clothes, caring for the house, take care [of] children because of the dominant power of the family and men.' This experience of course varies between households and individuals, but is an important consideration for how projects and organizations empower people to experience personal gender norms transformation.

Women who have powerful and senior roles at work or are outspoken activists might have limited power within their own households and feel somewhat helpless to change this. The idea of 'change within and personal transformation' can be more straightforward for men who have the freedom to change their behaviour: a freedom that often does not exist for women. Adding further complexity and challenge is that 1) male staff are not given guidance on how to change their behaviours positively (because a lot of focus is on women); and 2) there is often a perception or reality that men will have to relinquish some control in order for women to gain power or freedom, which can lead to resistance.

\section{Example 4: ISF-UTS employing transformative research frameworks}

A transformative research framework and collaborative partnership approach was employed to facilitate engagement between researchers and practitioners when working with East Meets West Foundation (EMW) in Cambodia. A transformative framework asks: What is the researcher's role with regard to the promotion of social justice? How can researchers address issues of power and inequities as a means to furthering human rights? How can the design focus on a methodology that can support social change ? (Mertens, 2009). The Institute for Sustainable Futures, University of Technology Sydney (ISF-UTS) led the research on women's empowerment in piped water schemes in rural Cambodia; the research was conducted in partnership with EMW and the Cambodian Water Association (CWA) to facilitate engagement between researchers and practitioners. This process included the co-development of research frameworks, interview questions, sampling processes, and joint analysis workshops as part of the transformative research approach. The approach was also important for facilitating research impact, as the users of the research were meaningfully and actively involved throughout the process, an established strategy for achieving research influence. ISF-UTS staff continually reflected on positionality in terms of power dynamics (as academics, as being from the Global North, as being funded by a large donor) in engagement with partners and interviewees, and negotiated roles and responsibilities for staff and partners that ensured their agency in the project was prioritized.

\section{Example 5: Sexual and gender minority training delivered by Edge Effect}

Working with sexual and gender minorities (SGM) is new for many development and humanitarian organisations, their staff and their partners. Edge Effect specialises in transformative approaches to working with SGM people, including as the SGM Advisor to the Water for Women Fund. Edge Effect's guidance for the Water for 
Women Fund highlights the need to work in genuine partnerships with SGM CSOs. Too often development organisations work at cross-purposes with SGM CSOs and communities. For example development project timeframes do not always align with the longer-term commitments that CSOs have with their communities. At other times, development organisations have taken extractive approaches to the expertise of SGM CSOs and communities or tokenistic approaches to inclusion that do not include payment for time or take into account the resource constraints of CSOs (Water for Women Fund et al 2020).

Edge Effect has also emphasised the need for development and humanitarian organisations to take a norms-based approach to addressing exclusion of sexual and gender minorities - also known as people with diverse SOGIESC (sexual orientation, gender identity/expression, and sex characteristics) or LGBTIQ+ people. Focusing on norms - rather than identity categories - is critical for transformation. This is because a norms focus highlights the source of exclusion, rather than what makes a certain group of people different (Water for Women Fund et al 2020). For SGM people the sources of exclusion include heteronormativity (the assumption that all people are or should be heterosexual) or cisnormativity (the assumption that all people's gender identity aligns with their sex-assigned-at birth) and the gender binary (the assumption that all people's gender identity fits in one of two boxes). These norms are expressed in laws, institutions and social practices, but are all present in the policy and practice of development organisations and the people who work within them. Edge Effect's training - attended by staff from several WASH sector organizations and researchers in Australia - helps development and humanitarian practitioners to reflect on their personal and organisational practice. For example, what constitutes a family or a household? Do we still make assumptions that families have a heterosexual relationship at their core? Would our systems recognise that a group of trans women living in an apartment might consider themselves 'chosen family' or see themselves as household? Many staff of development organisations enter these workshops with an open heart, but lack of familiarity with the issues and fear of doing harm are considerable hurdles (Water for Women Fund et al 2020).

\section{What do these examples reveal?}

These examples encourage self-examination of private and professional life before engaging in gender work, gender audits, and research on tackling social norms, biases, and attitudes among staff. This is not only related to staff mind-sets, but also about addressing workplace policies, systems, procedures, and structures. Nevertheless, it is noted that a lack of monitoring and evaluation (M\&E) is a gap in tracing the results of all these initiatives. While transformational thinking is critical for understanding gender norms and relations, it is not a guarantee that transformation will actually take place. Moving forward, some other gaps to consider are as follows:

- Are we as individuals and WASH actors willing to acknowledge, confront, and change deep-set, unconscious biases? 
- How do we train people effectively in this space? How can we support them to have deep and lasting emotional and behavioural changes?

- How do we avoiding solidifying existing attitudes or creating backlash?

- How do we agree what success looks like and how can we measure it?

\section{Ideas for action}

There are important steps - at the personal and organizational level - that can be taken immediately by everyone in the WASH sector to address the issues raised in this paper. If WASH actors are to be part of the solution, changes are needed at the individual level to address any deep-set biases and equally important, to address the structural constraints within organizations. The following recommendations are made to help us all improve our own thinking and ways of working as actors in the WASH space.

\section{Personal/individual change}

- Listen. Work on your personal listening skills, analyse your own communication style, and actively consider whether or not your listening abilities could be enhanced and how. Consider using a range of communications tools that allow for people to provide input and engage, beyond offering their opinion verbally in group settings.

- Stepping back if you have privilege. This includes recognizing one's own power and privilege; how that manifests in the workplace and community; and to make space for others who are normally not heard (Quakers, n.d.); for example, men specifically stepping back and giving space for women and girls and other gender-discriminated people to speak. Also allowing a range of ways that people can communicate, so that the spaces do not only privilege those with greatest confidence. Stepping aside from roles that might be performed more effectively by others with less privilege and actively putting others forward. For example, many men have joined the movement to end 'manels' which are all-male speaking panels.

- Practising critical self-awareness. Can we take steps to become aware of our (unconscious) biases and challenge these, working to change our perceptions, mind-sets, and actions, or at the very least raise our consciousness? Behavioural changes (or at least self-regulation) - at work as well as at home and in our personal relationships and private life - can occur when WASH staff are able to examine their prejudices and stereotypes.

- Practising reflexivity. This 'entails striving to be aware of personal biases, predilections and mental frames, and mental categories and pigeonholes for interpreting the world, and how power and relationships can distort what we know. It means reviewing and reflecting on these and trying to offset the distortions and misjudgements to which they give rise' (Chambers, 2017). There are simple ways for professionals to practise more reflexivity (seek feedback, keep a journal, team reflections, debrief and check-in sessions, etc.). 
Improving self-reflection, individual and organizational transformation will help organizations improve their own thinking, ways of working, and effectiveness as actors in the WASH space.

- Convene or join an informal network of practitioners, researchers, and academics from the WASH and gender minorities sectors, including Edge Effect's global community of practice, to support each other, to discuss, research, and explore further the specific needs of particular people (for example, sanitation and hygiene services for transgender and non-binary people).

- Actively take part in workshops and trainings, for example those that are focused on working with and being an ally to people within sexual and gender minorities.

- Better documentation of how WASH professionals' internal beliefs and attitudes, and even organizational structures, contribute to, at best, ignoring negative gender norms or, at worst, supporting and encouraging them (Cavill et al., 2018).

\section{Organizational change}

As recommend by Chambers (2017), and Examples 4 and 7, more reflective practice at headquarter level in donor countries rather than just in country offices.

- Practising allyship. As WASH actors can we act in solidarity with organizations and marginalized people? What does good allyship look like? For instance, men and boys are asked to be allies in the menstrual health and hygiene debate to help break barriers and taboos. Good allyship in this context means taking care to reflect on positionality and do this in partnership with girls and women and women's groups so that men and boys do not speak for, or speak over, women and girls. How can we support leadership within the contexts we are working, rather than boosting our own leadership opportunities? It is important to be aware of power dynamics between partners and to be sensitive to these dynamics - being careful not to reinforce unequal relations. In partnerships between NGOs and research organizations, resources can be drawn on to inform good allyship (for example see the Research for Development Impact (2017) Principles and Guidelines for Ethical Research and Evaluation).

- Creating a work environment that is truly transformative. Consistently applying a diversity and inclusion lens, welcoming all, and changing the structures that might produce and reproduce bias (such as HR policies on parental leave or sexual harassment). Self-assessments and confidential gender and equality audits can make visible the attitudes, norms, and structures of workplaces and organizations on gender equity and other forms of power and diversity, expose discrimination, and penalize discrimination when it occurs.

- Recruitment. Including questions on GESI and personal values in interviews and reference checks, as well as recruiting for diversity in WASH teams including representation of women and minority groups at all levels, including leadership.

- Group or team agreements on what is acceptable language and behaviour and what is not when working together as a team. For example, not cutting people off mid-sentence, and having a range of ways for people to contribute. Furthermore, 
having agreements on how to hold each other to account: that is, to not be a bystander. There are tools, such as the 'constructive conversation', for how to have those conversations in a respectful and constructive way.

- Creating space, time and budget within projects for teams to explore personal and professional transformation. This could be, for example, trying out different strategies for staff to reflect on their inherent power and unearned privilege, unconscious bias and patriarchal structures, attitudes and beliefs. Research is also needed to better understand the tensions between personal and professional values, structural and power influences, and the effect of the workplace on professional identities. It is also important for men to be facilitated to have time and space to reflect on how gender norms have influenced them and their life choices.

- Supporting trainings and workshops, especially those delivered by people from marginalized backgrounds - so we can hear directly from them. Elevate their voices wherever possible.

\section{Conclusions}

Why do you expect people to believe that another world is possible if you cannot create it in some small measure in this small limited space under your control? If we cannot help people experience, within social justice and feminist organizations, a microcosm of that just, inclusive, sustainable world or what that might actually feel like, look like, work like, what the hell are we talking about? (Srilatha Batliwala, Keynote at RDI Conference, 2019).

As WASH actors, we are becoming accustomed to supporting communities to work towards gender transformative change in order to achieve the intertwined and mutually dependent goals of SDG 5 and 6, but are we (personally and organizationally) willing to hold the mirror to ourselves? Are we investing enough in our own development, attitudinal change, and personal and professional practice in support of transforming gender norms? Recognizing that people within the WASH sector may ourselves be in some way sexist, ageist, racist, and ableist, this paper indicates that in order to be transformative we must change too, and we must invest time and resources into this change process. Through outlining some of the ways in which WASH organizations are approaching institutional change, we have identified an increasing awareness and commitment in a range of contexts to personal and professional change in support of gender equality and inclusion. This paper calls for the internalization of a transformative approach in the WASH sector itself (as WASH actors and organizations); in its attitudes, behaviours, workplace culture, facilities, staffing, research approaches, systems, and operations in order to achieve transformative change.

\section{Acknowledgments}

The open access fee for this document has been financed by the Swedish International Development Cooperation Agency, Sida. Sida does not necessarily share the views expressed in this material. Responsibility for its contents rests entirely with the authors. 


\section{References}

A Call to Men (no date) 'Embrace a healthy respectful manhood' [online] <https://www. acalltomen.org/impact-healthy-manhood> [accessed 29 April 2020].

Agora (no date) 'HeforShe: Building Gender IQ' [online] <https://agora.unicef.org/course/info. php?id=7107> [accessed 29 April 2020].

Aronson, E., Wilson, T.D. and Akert, A.M. (2005) Social Psychology, 5th edn, Prentice Hall, Upper Saddle River, NJ.

Department of Foreign Affairs and Trade (2012) Civil Society, Water Sanitation and Hygiene (CS WASH) Fund: Design Document [online] <https://dfat.gov.au/about-us/publications/Pages/ civil-society-water-sanitation-and-hygiene-wash-fund-design-document.aspx $>$ [accessed 29 April 2020].

Batliwala, S. (2011) Feminist Leadership for Social Transformation: Clearing the Conceptual Cloud [pdf], CREA <https://www.uc.edu/content/dam/uc/ucwc/docs/CREA.pdf > [accessed 29 April 2020].

Batliwala, S. (2019) 'Srilatha Batliwala Keynote at RDI Conference 2019' [video] <https://www. youtube.com/watch? $\mathrm{v}=$ ogEu8Sp1mFk $>$ [accessed 29 April 2020].

Boyce, P., Brown, S., Cavill, S., Chaukekar, S., Chisenga, B., Dash, M., Dasgupta, R.K., Brosse, N.D.L., Dhall, P., Fisher, J., Gutierrez-Patterson, M., Hemabati, O., Hueso, A., Khan, S. Khurai, S., Patkar, A., Nath, P., Snel, M. and Thapa, K. (2018) 'Transgender-inclusive sanitation: insights from South Asia', Waterlines 37(2): 102-17.

Byanyima, W. (2019) 'We must learn and change after Haiti sexual abuse scandal - Oxfam chief' [online], World Economic Forum <https://www.weforum.org/agenda/2019/06/facinghard-truths-to-tackle-the-causes-of-sexual-abuse/> [accessed 29 April 2020].

CARE (2008) Inner Spaces Outer Faces Initiative: Toolkit: Tools for Learning and Action on Gender and Sexuality [pdf] <https://www.care.org/sites/default/files/documents/MH-2008-ISOFIToolkit_2008.pdf> [accessed 29 April 2020].

CARE (2017) Gender Transformative Change: Flagship Approach [pdf] <https://www.careindia. org/wp-content/uploads/2017/10/CARE_India_GTC_FLagship_Approach_Sept20171.pdf> [accessed 29 April 2020].

Cavill, S., Mott, J. and Tyndale-Biscoe, P., with Bond, M., Huggett, C. and Wamera, E. (2018) 'Engaging men and boys in sanitation and hygiene programmes', Frontiers of CLTS: Innovations and Insights 11, IDS, Brighton, UK.

Chambers, R. (2017) Can We Know better? Reflections for Development [online], Practical Action Publishing, Rugby, UK <https://www.developmentbookshelf.com/doi/pdf/10.3362/ 9781780449449> [accessed 29 April 2020].

Charity Commission for England and Wales (2020) Statement of the Results of an Inquiry: The Save the Children Fund (Save the Children UK), Charity Commission for England and Wales.

Cortina, L.M., Kabat-Farr, D., Leskinen, E.A., Huerta, M. and Magley, V.J. (2013) 'Selective incivility as modern discrimination in organizations: evidence and impact', Journal of Management 39(6): 1579-605.

Department of Foreign Affairs and Trade (DFAT) (no date) Water for Women Fund [online] $<$ https://www.waterforwomenfund.org/en/index.aspx> [accessed 4 May 2020].

Dickin, S. and Bisung, E. (2019) Empowerment in WASH Index, SEI Discussion Brief, October 2019, Stockholm Environment Institute, Stockholm. 
Dictionary.com (no date) 'Gender and Sexuality Dictionary: positionality' [online] <https:// dictionary.com/e/gender-sexuality/positionality/> [accessed 29 April 2020].

Edge Effect (no date) 'Our purpose' [online] <https://www.edgeeffect.org/our-purpose/> [accessed 29 April 2020].

Essed, P. (1991) Understanding Everyday Racism: An Interdisciplinary Theory, Vol. 2, Sage, Thousand Oaks, CA.

Eyben, R. and Turquet, L. (eds.) (2013) Feminists in Development Organizations: Change from the Margins, Practical Action Publishing, Rugby, UK.

Government of Canada (2017) Canada's Feminist International Assistance Policy [online] $<$ https://www.international.gc.ca/world-monde/issues_development-enjeux_developpement/ priorities-priorites/policy-politique.aspx?lang=eng > [accessed 29 April 2020].

Government Offices of Sweden (no date) 'Feminist foreign policy' [online] <https://www. government.se/government-policy/feminist-foreign-policy/> [accessed 29 April 2020].

Grant, M., Murta, J., Willetts, J., Carrard, N. and Powell, B. (2016) Civil Society Organisations' Learning for Impact in Water, Sanitation and Hygiene Programming [pdf], CS WASH Fund <https://www.uts.edu.au/sites/default/files/CSO_Learning_for_Impact_Report.pdf > [accessed 29 April 2020].

Grant M., Willetts J. and Huggett, C. (2017) Gender Equality and Goal 6 - The Critical Connection: An Australian Perspective, Australian Water Partnership, Canberra <http://waterpartnership. org.au/>.

Grant, M., Soeters, S., Bunthoeun, I. and Willetts, J. (2019a) 'Rural piped-water enterprises in Cambodia: a pathway to women's empowerment?' Water 11: 2541.Grant, M., Willetts, J. and Huggett, C. (2019b) Gender Equality and Goal 6 - The Critical Connection: An Australian Perspective [pdf], Australian Water Partnership, Canberra <https://waterpartnership.org.au/ wp-content/uploads/2019/08/Gender-Equality-and-Goal-6-The-Critical-Connection.pdf> [accessed 4 May 2020].

Gupta, R.G. (2001) 'Gender, sexuality, and HIV/AIDS: the what, the why, and the how', SIECUS Report 29(5): 6(7).

Institute for Sustainable Futures (ISF) UTS (2019) 'Water for Women Research' [online] $<$ https://waterforwomen.uts.edu.au/news/> [accessed 29 April 2020].

Longwe, S.H. (1999) Women's Empowerment (Framework): A Guide to Gender Analysis Frameworks, Oxfam GB, Oxford.

Male Champions of Change (no date) Home page [online] <https://malechampionsofchange. com/> [accessed 29 April 2020].

Mertens, D.M. (2009) Transformative Research and Evaluation, Guilford Press, New York.

Moser, C. (1989) 'Gender planning in the third world: meeting practical and strategic gender needs', World Development 17: 1799-825.

Nath, P., Hueso, A. and Downie, E. (2017) 'Toilets for everyone - moving to gender neutral bathrooms in our London office', 16 November 2017 [online] <https://washmatters.wateraid. $\mathrm{org} / \mathrm{blog} /$ toilets-for-everyone-moving-to-gender-neutral-bathrooms-in-our-london-office> [accessed 29 April 2020].

Office of Diversity and Outreach, University of California (no date) 'Unconscious bias' [online] $<$ https://diversity.ucsf.edu/resources/unconscious-bias> [accessed 29 April 2020]. 
Plan International (2018) 'Gender and WASH Monitoring Tool (GWMT)' and 'GWMT Training Guide (2018 version)' [online] <https://www.plan.org.au/learn/how-we-work/ resources $>$ [accessed 29 April 2020].

Quakers (no date) Toolkit for Action: Owning Power and Privilege [online] <https://quaker-prod. s3.eu-west-1.amazonaws.com/store/6d94d334d4cdd158fbc8e21906be4cccb83bdf74cb2fbdaf9 7c523a98f45> [accessed 29 April 2020].

Quillian, L. (2006) 'New approaches to understanding racial prejudice and discrimination', Annual Review of Sociology 32: 299-328.

RedR (2016) Report: Inclusion and Security of LGBTI Aid Workers [pdf] <https://www.redr. org.uk/RedR/media/RedR/Training\%20and\%20Learning/Resources/LGBTI\%20Inclusion/ RedR-and-EISF-2016-REPORT-INCLUSION-AND-SECURITY-OF-LGBTI-AID-WORKERSWORKSHOP-22-01-2016.pdf> [accessed 29 April 2020].

Research for Development Impact (RDI) Network (2017) Principles and Guidelines for Ethical Research and Evaluation [online], Australian Council for International Development <https:// rdinetwork.org.au/effective-ethical-research-evaluation/principles-guidelines-ethical-researchevaluation/> [accessed 29 April 2020].

Re:work (no date) 'Unbiasing' [online] <https://rework.withgoogle.com/subjects/unbiasing/> [accessed 4 May 2020].

Rowe, M.P. (1990) 'Barriers to equality: the power of subtle discrimination to maintain unequal opportunity', Employee Responsibilities and Rights Journal 3(2): 153-63.

Smith, L. (no date) '\#ABLEISM' [blog], Centre for Disability Rights <http://cdrnys.org/blog/ uncategorized/ableism/> [accessed 29 April 2020].

Soeters, S., Grant, M., Carrard, N. and Willetts, J. (2019) Intersectionality: Ask the Other Question [pdf], Water for Women: Gender in WASH - Conversational article 2, Institute for Sustainable Futures, University of Technology Sydney <https://s3-ap-southeast-2.amazonaws. com/wordpress.multisite.prod.uploads/wp-content/uploads/sites/57/2019/03/05175814/ ISF-UTS_2019_IntersectionalityArticle2_GenderinWASH_WaterforWomen.pdf> [accessed 30 April 2020].

Sue, D.W., Capodilupo, C.M., Torino, G.C., Bucceri, J.M., Holder, A., Nadal, K.L. and Esquilin, M. (2007) 'Racial microaggressions in everyday life: implications for clinical practice', American Psychologist 62(4): 271-86.

Tutor2U (no date) 'Psychology: types of conformity' [online] <https://www.tutor2u.net/ psychology/reference/types-of-conformity> [accessed 30 April 2020].

University of Leeds (no date) 'Nakuru Accord: Failing better in the WASH sector' [blog] <https://wash.leeds.ac.uk/failing-better-in-the-wash-sector/> [accessed 30 April 2020].

Van Wijk-Sijbesma, C. (1987) 'Drinking-water and sanitation: women can do much', World Health Forum 8(1): 28-33.

Water for Women Fund et al (2020) 'Stepping Up: ensuring sexual and gender minorities are not left behind', Learning brief - Systems Strengthening/Leave No One Behind. <https://www. edgeeffect.org/wp-content/uploads/2020/04/EdgeEffect_Stepping-Up_Full-Report.pdf> 